\title{
Storage Technique for Atomic Hydrogen
}

\section{Citation}

Berg, Howard C., and Daniel Kleppner. 1962. Storage technique for atomic hydrogen. Review of Scientific Instruments 33(2): 248-249.

\section{Published Version}

http://dx.doi.org/10.1063/1.1746584

\section{Permanent link}

http://nrs.harvard.edu/urn-3:HUL.InstRepos:3196302

\section{Terms of Use}

This article was downloaded from Harvard University's DASH repository, and is made available under the terms and conditions applicable to Other Posted Material, as set forth at http:// nrs.harvard.edu/urn-3:HUL.InstRepos:dash.current.terms-of-use\#LAA

\section{Share Your Story}

The Harvard community has made this article openly available.

Please share how this access benefits you. Submit a story.

Accessibility 


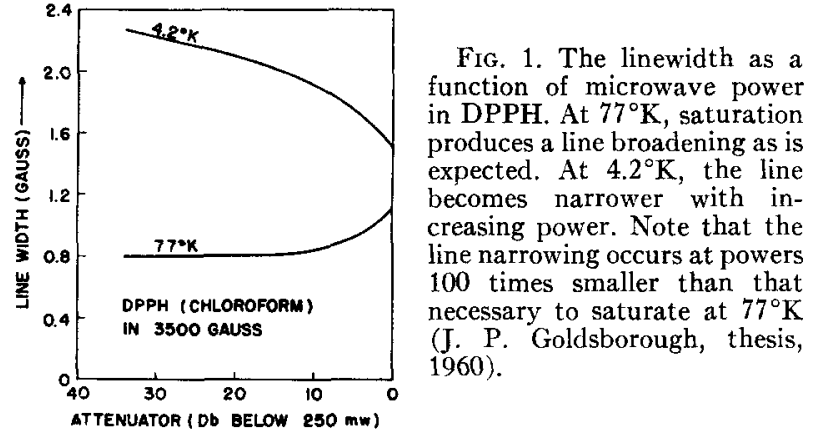

lattice or exchange specific heat. ${ }^{1}$ Substances with very short spin-lattice relaxation times such as the free radicals $\alpha, \alpha$-diphenyl $\beta$-picryl hydrazyl (DPPH) and $\alpha, \gamma$-bisdiphenylene $\beta$-phenyl allyl (BDPA) ${ }^{2}$ require large amounts of microwave power for saturation. Under these conditions the usual $\mathrm{CW}$ saturation experiment may be measuring the lattice-bath bottleneck and not the true spin-lattice relaxation time. In the case of DPPH and BDPA it was comparatively simple to recognize that, in attempting to saturate the resonance line, we were heating the lattice. The linewidths of DPPH and BDPA have an inverse temperature dependence in the liquid helium temperature range. ${ }^{3}$ In Fig. 1 we see what happens to the linewidth of DPPH saturated at $77^{\circ} \mathrm{K}$ where the lattice specific heat is large. The broadening of the resonance line as the incident power is increased is that predicted by the Bloch equations. At $4.2^{\circ} \mathrm{K}$, however, we see that the linewidth narrows as the microwave power is increased. This narrower line is the unsaturated line corresponding to a higher lattice temperature.

We have developed a modulated $\mathrm{CW}$ method in which the microwave power remains on for a time long compared to that necessary for the electrons to reach equilibrium with the microwaves. This characteristic time, obtained by solving the rate equations for a spin $\frac{1}{2}$ system is given by $T_{1} /\left(1+\gamma^{2} H_{1}^{2} T_{1} T_{2}\right)$. However, the duty cycle is such that the average power is not sufficient to appreciably heat the

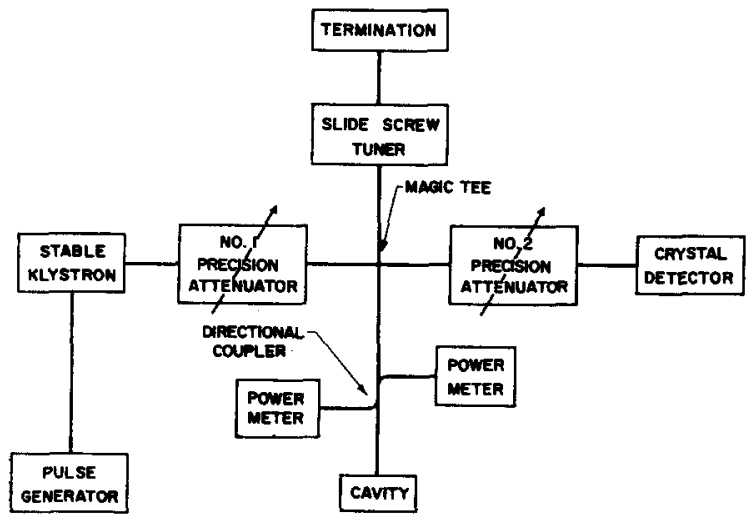

FIf. 2. Essential microwave components of the magnetic resonance spectrometer. lattice. One can make $T_{1}$ measurements at several values of the duty cycle to see if heating effects have been eliminated.

An X-band bridge spectrometer is used, as shown in Fig. 2. One sets the magnetic field on resonance and then moves the klystron by means of the reflector voltage off magnetic and klystron resonance. The pulse height is then turned up to bring the system back on magnetic resonance. Since the AFC can not be used during this operation an extremely stable klystron is required. We use magnetic field modulation with phase-sensitive detection. The use of magnetic field modulation requires that the pulse rate be greater than the modulation frequency. Instead of field modulation, the phase-sensitive detector could operate at the frequency of the pulse-repetition rate. Saturation measurements are made in the usual $\mathrm{CW}$ manner. As the power incident on the cavity is increased by decreasing the attenuation in attenuator 1, the setting of 2 is increased so that the power falling on the crystal is constant (see Fig. 2).

We have applied this technique to measure the relaxaation time of polycrystalline $\mathrm{DPPH}^{4}$ and BDPA. At 300 and $77^{\circ} \mathrm{K}$ both the usual $\mathrm{CW}$ and our modulated $\mathrm{CW}$ method give the same results, $T_{1} \sim 5 \times 10^{-8} \mathrm{sec}$ for DPPH and $\sim 1 \times 10^{-7} \mathrm{sec}$ for BDPA. Previous microwave measurements, both $\mathrm{CW}$ and high power pulse, ${ }^{5}$ on DPPH and BDPA at $1.5^{\circ} \mathrm{K}$ had given values of $T_{1}$ around $10^{-6} \mathrm{sec}$, while our modulated $\mathrm{CW}$ method gives $T_{1} \sim 10^{-8} \mathrm{sec}$.

The author wishes to thank Professor James Burgess for many helpful discussions.

* Supported by the U. S. Air Force Office of Scientific Research. † Presently employed with General Telephone and Electronics Laboratories, Inc., Palo Alto, California.

${ }^{1}$ M. W. P. Strandberg, Phys. Rev. 110, 65 (1958).

2 J. P. Goldsborough, M. Mandel, and G. E. Pake, Phys. Rev. Letters 4, 13 (1960).

${ }^{3} \mathrm{~J}$. P. Goldsborough, thesis, Stanford University.

${ }^{4}$ M. Mandel, G. E. Pake, and J. P. Goldsborough, Bull. Am. Phys. Soc. 6, 141 (1961).

${ }^{5}$ James W. Meyer, thesis, Massachusetts Institute of Technology.

\section{Storage Technique for Atomic Hydrogen*}

\author{
Howard C. Berg $\dagger$ AND Daniei Kleppner \\ Harvard University, Cambridge, Massachusetls
}

(Received November 15, 1961)

WE have found it possible to inhibit adsorption and surface recombination of atomic hydrogen by covering the container with a thin film of Teflon. The storage time of hydrogen has been measured with the atomic hydrogen maser, ${ }^{1}$ and times of up to $2.5 \mathrm{sec}$ have so far been obtained, corresponding to $7.5 \times 10^{4}$ wall collisions. This is appreciably longer than possible with a saturated hydrocarbon coating, such as paraffin, or with a surface treated with Dri-Film ${ }^{2}$ (dimethyldichlorosilane). The pressure of atomic hydrogen in the maser is of the order of $10^{-7} \mathrm{~mm} \mathrm{Hg}$, 
although much higher pressures could be used before threebody collisions become important. On the basis of hyperfine frequency measurements we conclude that wall collisions not leading to chemical reaction are essentially elastic with an interaction time of the order of $10^{-13}$ sec.

The chief mechanism by which hydrogen is lost on collision with a saturated hydrocarbon surface is thought to be chemical reaction with the surface. A typical reaction would be of the form $\mathrm{H}+\mathrm{CH}_{3} \rightarrow \mathrm{H}_{2}+\mathrm{CH}_{2}$. The activation energy for such a reaction is consistent with the relaxation rate measured with the maser. The activation energy for the corresponding reaction with a saturated fluorocarbon is substantially higher and vastly longer lifetimes are therefore to be expected. The measured lifetime of $7.5 \times 10^{4}$ collisions is a lower limit, since the geometry of the bulb and several other factors serve to limit the hyperfine radiation lifetime of the atoms, which is the quantity measured.

The Teflon we have used is an aqueous suspension made by duPont (Teflon Clear Finish 852-201). The container to be coated, which in our case is a quartz bulb, is cleaned with hot glass cleaning solution (sulfuric acid-dichromate), rinsed several times, and drained. The same treatment is satisfactory with a Pyrex vessel. The Teflon suspension is strained and diluted with distilled water to about the consistency of skim milk. A thin coating is applied by swishing the solution in the bulb and then draining it out. The coating is quickly dried by flowing dry $\mathrm{N}_{2}$ through the bottle and heating the outside with a hot air gun. The coating must be fused, and this is accomplished by heating the bulb locally with an air-acetylene torch. Teflon fuses to a clear, nearly colorless film at about $400^{\circ} \mathrm{C}$, and decomposes rapidly only well above this temperature. The finished film is cleaned gently with hot cleaning solution and rinsed.

If the coating is too thick it tends to turn brown and crack; if it is too thin it is very fragile. The consistency of the Teflon suspension is therefore critical.

The authors wish to thank G. B. Kistiakowsky for a very helpful discussion on surface reactions.

* Work supported by the National Science Foundation.

$\dagger$ National Institutes of Health Predoctoral Fellow.

${ }^{1}$ H. M. Goldenberg, D. Kleppner, and N. F. Ramsey, Phys. Rev. Letters 5, 361 (1960).

${ }^{2}$ J. P. Wittke and R. H. Dicke, Phys. Rev. 103, 620 (1956).

\section{Fast-Response Temperature-Control Unit for a Spectroscopic Sample Chamber}

\author{
StD Deutsch \\ The Rockefeller Institute, New York, New York
}

(Received August 16, 1961; and in final form, November 14, 1961)

$\mathrm{T}$ EMPERATURE-DEPENDENT changes in certain protein solutions may be studied by spectroscopic analysis. The temperature of $\mathbf{1 . 5} \mathrm{cc}$ of liquid in a standard optical cuvette may be controlled to within $1^{\circ} \mathrm{C}$ at any
Fig. 1. Heating coil in a $1-\mathrm{cm}^{2}$ cuvette.
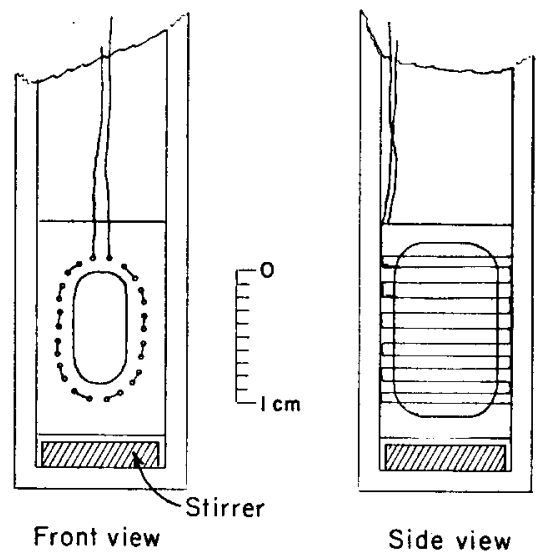

setting above the ambient temperature, between 20 and $100^{\circ} \mathrm{C}$, with the instrument described in this note. The temperature increases at a $5^{\circ} \mathrm{C} / \mathrm{sec}$ rate toward the desired preset temperature value. The unit includes four unorthodox features, as follows:

(1) The heating coil is directly immersed in the liquid. As shown in Fig. 1, the container is a $1-\mathrm{cm}^{2}$ cuvette. The oval opening in the front view allows unobstructed passage of an infrared beam for spectroscopic analysis of the liquid. The heating coil is wound on a Kel-F form that is hollowed out so that only a neglibigle portion of the coil is lost for heating purposes. The wire criss-crosses along a path that runs parallel to the oval opening. A rigid extension of the Kel-F frame that is used to support lead wires as well as various solution tubes has been omitted from the drawing. To prevent chemical interactions with the liquid, a relatively inert platinum wire (No. 40 bare, 0.003 in. diam) is used. The coil resistance is about $7.2 \mathrm{ohms}$. The small stirrer at the bottom of the cuvette is magnetically rotated.

(2) The heating coil also acts as an arm of the temperature-control Wheatstone bridge. The circuit is illustrated in Fig. 2. Sixty-cycle heater power is supplied to $R_{1}$ through $\mathrm{L}_{R}$ and $\mathrm{C}_{R}$ at the same time that a 2-v dc bridge supply is applied through $\mathrm{L}_{\mathrm{F}}$. The latter blocks ac while $\mathrm{C}_{\mathrm{R}}$ blocks dc.

(3) The reactive elements $L_{R}$ and $C_{R}$ form a partially series-resonant circuit at $60 \mathrm{cps}$. This allows $30 \mathrm{w}$ of heater power to reach $R_{1}$ with a relatively small value for $C_{R}$.

(4) The $30 \mathrm{w}$ of power are applied only to $R_{1}$ in contrast with a balanced arrangement ${ }^{1}$ in which an additional $30 \mathrm{w}$ would be dissipated in $\mathbf{R}_{\mathbf{2}}$. A balanced circuit would also require an isolation transformer because neither side of the heater supply could be at ground. The relatively large ac output of the circuit shown is removed by a 2 -sec $R_{F} C_{F}$ time constant. The use of only 200 ohms for $\mathrm{R}_{\mathrm{F}}$ yields a low source resistance for the amplifier. $C_{F}$ consists of two low-voltage electrolytics in series, with reversed polarities, to handle either dc polarity.

Before a temperature run, the experimenter ${ }^{2}$ places the unit in a "stand-by" position, thereby returning the Variac 